\title{
EVALUATION OF PROCOAGULANT POTENTIAL OF ENDOTHELIAL MICROPARTICLES CD144 IN DIABETIC AND NON-DIABETIC ACUTE CORONARY SYNDROME PATIENTS.
}

\author{
By \\ Shahir K. George (M.D); Azza Abdel Baky (M.D)*; \\ Amany H. Mansour (M.D)^ and Nora M. El-Shabrawy (M.Sc.)* \\ From \\ Department of Cardiology, Department of Clinical Pathology*, \\ Faculty of Medicine, Mansoura University
}

\begin{abstract}
Background: Acute

coronary

syndrome (ACS) is a potentially life threatening manifestation of coronary artery disease $(C A D)$. Apoptotic microparticles are responsible for almost all tissue factor activity of the plaque lipid core. The elevated levels of procoagulant microparticles could also circulate in the peripheral blood of patients with recent clinical signs of plaque disruption and thrombosis. Subjects and Methods: The present study included 60 acute coronary syndrome (ACS) adult patients selected from Cardiology Department in Mansoura Specialized Hospital, Mansoura University during the period between February 2013 to November 2013. Group I: comprised
\end{abstract}

30 diabetic patients presented with ACS. Group II: comprised 30 nondiabetic patients presented with ACS and 25 healthy subjects as a control group. ACS patients were further classified according to laboratory and radiological findings (Troponin test and ECG) into: Group A: comprised 16 ST segment elevation myocardial infarction (STEMI) patients. Group B: comprised 19 non ST segment elevation myocardial infarction (NSTEMI) patients. Group C: comprised 25 unstable angina patients. Traditional laboratory investigations and special laboratory assessment of CD144 FITC by flow cytometry were done. Results: the present study revealed highly elevated CD144 percentages in diabetic

MANSOURA MEDICAL JOURNAL 
ACS patients compared to healthy controls $(P=<0.0001)$, highly elevated CK-MB, fasting sugar, total cholesterol (TC), triglyceride (TG), and LDL cholesterol $(P=0.0001$, $\mathrm{P}=0.0001, \mathrm{P}=0.0002, \mathrm{P}=0.0002$ and $\mathrm{P}=0.0001$ respectively). In contrast, non diabetic ACS patients had significantly elevated CD144, CK-MB, TC, TG and LDL $(P=0.0001, P=0.0001$, $\mathrm{P}=0.0001, \mathrm{P}=0.0021$ and $\mathrm{P}=0.0021$ respectively) while fasting blood sugar and $\mathrm{HbA1c}$ were non significantly changed. On the other hand group $B$ (NSTEMI) patients had significantly elevated CD144 percent in comparison to patients with unstable angina (group $c)(P=0.05)$ but patients with group A (STEMI) had significantly elevated CK-MB compared to patients with unstable angina (group c) $(P=0.02)$. Conclusion: The high levels of CD144 circulating microparticles of endothelial origin are increased in diabetic patients with coronary artery disease (CAD) suggesting an important role for endothelial injury in prediction of ACS. Hyperglycemia in acute coronary syndrome is associated with enhanced local thrombin generation and platelet activation, as well as unfavorably altered clot features in patients with and without a previous history of diabetes.

Keywords: microparticls, acute coronary syndrome, platelets microparticls, endothelial microparticles

\section{INTRODUCSTION}

Cardiovascular disease (CVD) is a major global cause of mortality in the developed countries. Acute coronary syndrome (ACS) is a potentially life threatening manifestation of coronary artery disease (CAD). ACS is defined as a constellation of symptoms consistent with acute myocardial ischemia, including unstable angina (UA), non-ST segment elevation myocardial infarction (NSTEMI) and ST-segment elevation myocardial infarction (STEMI). Intravascular thrombogenesis, the main pathogenic mechanism of the CAD, is influenced by a complex interplay of procoagulant, anticoagulant, fibrinolytic, endothelial damage/dysfunction and inflammatory processes (1).

Chest pain (or discomfort) is the leading chief complaint of patients found to have ischemic heart disease (2). The majority of acute coronary artery diseases are precipitated by vascular occlusion caused by atherosclerotic plaque disruption, plate-

Vol. 43, No. 1 \& 2 Jan. \& April, 2014 
let aggregation, platelet adhesion, (EMPs) can be identified and measand the resulting intravascular ured by detection of antigens constitthrombosis. Systems that are in- utively expressed by mature endovolved in maintaining the integrity thelial cells (ECs) [e.g. CD31 and patency of the vasculature in- (platelet derived growth factor), cluding endothelial and platelet func- CD105 (endoglin), CD144 (vascular tion, coagulation, and fibrinolysis are endothelium cadherin), CD146, etc impaired in diabetes, thereby shifting (6). There are strong associations the balance to favor thrombus forma- between high values of EMPs tion. The endothelium can shed mi- (CD31+, CD51+, CD144+) and varicroparticles (MP) as a result of cell ous vascular structural and functionactivation or apoptosis. MP were de- al abnormalities. Annexin V+/CD31+ fined as small vesicular structures EMPs correlate with vasodilatory enwithin heterogeneous diameter (from 0.1 to 1 micron), resulting from the remodeling of membrane phospholipids and expressing phosphatidylserine (PS) and antigens representative of their parent cells (3). Endothelial dysfunction (ED) plays an important role in the pathogenesis and clinical expression of atherosclerosis. It has been linked to Type II DM and insulin resistance states such as obesity in experimental and clinical studies (4). This reflects a number of abnormalities that include loss of bioavailable nitric oxide (NO), increased production of vasoconstrictors, and disturbed regulation of inflammation, thrombosis, and cell growth in the vascular wall.(5)

Circulating endothelial cell MPs dothelial dysfunction and have been shown to have potential as a marker of coronary endothelial function, independent of classic cardiovascular risk factors $(7,8)$. Furthermore, therapeutic improvement of endothelial function has been associated with a reduction of circulating EMP levels (9). EMP are also known to be elevated in condition associated with endothelial injury, as in acute coronary syndromes (10). Patients with different cardiovascular risk factors have significant up-regulation of EMPs before the development of coronary artery disease (CAD) (11). For example, various EMP types (CD144+, CD31+, CD51+ and annexin $\mathrm{V}_{+}$) are increased in diabetic patients, and appear to be good predictors of CAD (12). Diabetes not 
only increases the risk of myocardial infarction (MI) but also increases the mortality associated with the acute event. Hyperglycemia in acute coronary syndrome is associated with enhanced local thrombin generation and platelet activation, as well as unfavorably altered clot features in patients with and without previous history of diabetes. Acute hyperglycemia occurs in up to $50 \%$ of all STsegment elevation myocardial infarctions (13), whereas patients with diabetes represent $\sim 25 \%$ of patients with ST-segment elevation myocardial infarctions. When glucose tolerance testing is performed, $65 \%$ of patients with myocardial infarction and a negative history of diabetes can be diagnosed with diabetes or impaired glucose tolerance (14). The aim of this study is to assess the levels of procoagulant microparticles CD144 in diabetic and non-diabetic acute coronary syndrome patients and to evaluate its role in prediction of acute coronary events in these patients. Also to assess local thrombin generation and platelet activation, in ACS patients.

\section{SUBJECTS \& METHODS}

The present study included 60 ACS adult patients (46 males and 14 females) selected from Cardiology Department in Mansoura Specialized Hospital, Mansoura University during the period between February 2013 to November 2013. Twenty five healthy subjects with matched age, sex and BMI were included as healthy controls. The initial diagnosis of ACS was based on history, risk factors and ECG findings. This diagnosis required a combination of two of the following: typical ischemic chest pain, ECG changes and elevation of cardiac enzymes mainly Troponin and $\mathrm{CK}-\mathrm{MB}(1)$. Diagnosis of unstable angina included those patients with resting typical chest pain that last $>20$ minutes or patients with new onset angina or increasing (crescendo angina) that become more intense, of longer duration or more frequent or those with shortness of breath that could be angina equivalent (1). They were classified according to presence or absence of DM into the following groups: Group I: Comprised 30 patients (22 males and 8 females) with DM presented with acute coronary syndrome. Their ages ranged from 35 to 70 years. Group II: Comprised 30 non diabetic patients (24 males and 6 females) presented with ACS. Their ages ranged from 40 to 70 years. Healthy

Vol. 43, No. 1 \& 2 Jan. \& April, 2014 
controls: Comprised 25 healthy subjects (18 males and 7 females). Their ages ranged from 38 to 65 years. Acute coronary syndrome patients were further classified according to laboratory and radiological finding (Troponin test and ECG) into the following groups: Group A: Comprised 16 STEMI patients. Group B: Comprised 19 NSTEMI patients. Group C: Comprised 25 unstable angina patients. A written consent was signed from every participant. All study participants were subjected to full history taking, clinical examination, radiological and laboratory investigations including traditional laboratory investigations and special laboratory assessment of CD144 FITC by flowcytometry: 1- Complete blood count $(\mathrm{CBC})$ : including hemoglobin, RBC, WBC and platelets count. 2- Liver function tests including aspartate aminotransferase (AST), alanine aminotransferase (ALT), serum albumin and bilirubin levels, serum creatinine, fasting blood glucose, lipid profile including (total cholesterol, TG, HDL, LDL), glycated hemoglobin (HbA1c) and cardiac markers: CK-MB and Troponin. 3- Measurement of thrombin generation: Plasma levels of haemostatic markers, including thrombin antithrombin complex (TAT), was measured by using commercially available enzyme- linked immunosorbent assay (ELISA) kits (Dade Behring). 4- Special laboratory investigation: CD144 microparticles by flowcytomeric analysis. * Sample collection: After overnight fast, $7 \mathrm{ml}$ venous blood sample was obtained from every participant. They were divided into: $2 \mathrm{ml}$ on EDTA $(1 \mathrm{mg} / \mathrm{ml})$ for $\mathrm{CBC}$ and $\mathrm{HbA1c}, \mathrm{CD} 144$ and $5 \mathrm{ml}$ into plain tubes and serum samples were separated for traditional investigations.

Flowcytometry analysis was performed by kit supplied by DAKO Using coulter ${ }^{(15)}$. Briefly, $10 \mu \mathrm{l}$ of florescin isothiocyanate (FITC) conjugated monoclonal mouse antihuman CD144 antibodies were added and mixed with $100 \mu \mathrm{l}$ of fresh EDTA blood sample and was incubated at dark for $30 \mathrm{~min}$. A lysing reagent was added in order to lyse the red cells and separate the mononuclear cells. The cells were washed twice with phosphate buffered saline (PBS) containing $2 \%$ bovine serum albumin. Supernatant was removed and the cells were suspended in an appropriate medium. Negative controls were included in each run to de-

MANSOURA MEDICAL JOURNAL 
termine cut - off value between negative and positive population of cells. Analysis on flow cytometery within one hour using forward \& side scatter. Gating on mononuclear cell population was used for analysis of samples. Mononuclear cells were separated from bone marrow samples of controls and patients by Ficoll Hypaque density gradient centrifugation (Sigma Chemicals, St Louis, MO, USA). The separated cells were washed twice using PBS and the count in the suspension was adjusted to be $5 \times 10^{6} / \mathrm{ml}$. Data were displayed on two histograms: Histogram I: Two-parameter histograms (FS vs. SS). Histogram II: usually displayed as the mean fluorescence intensity (MFI) value of CD144.

\section{STATISTICAL ANALYSIS}

Results were collected, tabulated and statistically analysed using statistical package SPSS version 16 (SPSS INC, Chicago, IL, USA). Two types of statistics were done. Data were presented using mean, standard deviation (SD), standard error of mean (SEM). One way ANOVA is a test of significance used for comparison between three or more groups normally distributed having quantitative variables. Independent sample t-test is a test of significance used for comparison between two groups normally distributed having quantitative variables. Mann Whitney test (non parametric test) is a test of significance used for comparison between two groups not normally distributed having quantitative variables. Pearson's correlation is a test of significance used to measure the association between two quantitative variables. Level of significance was set as $p$-value $\leq 0.05$.

\section{RESULTS}

Table (1) demonstrates that there are no significant differences regarding age in all studied groups. Higher percentage of males $(72-80 \%)$ in comparison to females $(20-28 \%)$ in all groups. The percentage of hypertensive patients is $26.6 \%$ in group I but $20 \%$ in group II. The smoking percentage is $46.6 \%$ in group I and $30 \%$ in group II.

Table (2) represents comparison between 3 cardinal groups for CD144, CPK, CKMB, fasting blood sugar, HbA1c, TC, TG, HDL-c and LDL-C concentration. The following are noted: CD144, CPK, CKMB, TC, TG, and LDL-C are significantly higher in group I and II in compari- 
Shahir K. George et al...

son to healthy controls while there is significant reduction in HDL-c. Fasting plasma glucose and $\mathrm{HbA1C}$ are significantly higher in group I in comparison to healthy controls but no significant differences in group II in comparison to healthy control group. There are significant differences in CD144, CRP, TAT, fasting blood sugar, $\mathrm{HbA} 1 \mathrm{c}$ and $\mathrm{TG}$ in comparison between group I and group II.

Table (3) illustrates that CK-MB is significantly higher in group $A$ in comparison to group $C$ and platelet count and CD144 is significantly higher in group $B$ in comparison to group C.

Table (4) shows elevation of CD144 +ve EMP in smoker compared to non-smoker diabetic acute coronary syndrome patients (Group I). Also significant elevation is noted in hypertensive compared to normotensive diabetic ACS patients (Group I). No significant differences are noted between smoker and non-smoker non diabetic acute coronary syndrome patients but there is significant differences noted between hypertensive and normotensive patients in this group (Group II).

Table (1): Clinical characteristics of study and control groups

\begin{tabular}{|l|c|c|c|c|}
\hline & $\begin{array}{c}\text { Healthy control } \\
\text { (n 25) }\end{array}$ & $\begin{array}{c}\text { Group I } \\
\text { (n 30) }\end{array}$ & $\begin{array}{c}\text { Group II } \\
\text { (n 30) }\end{array}$ & P \\
\hline Men/Women & $15 / 10$ & $22 / 8$ & $24 / 6$ & 0.3 \\
\hline Age (year) & $53 \pm 6.6$ & $55.7 \pm 9.9$ & $55.3 \pm 7.2$ & 0.6 \\
\hline BMI,kg/m2 & $24.4 \pm 0.9$ & $24.0 \pm 0.2$ & $24.3 \pm 0.8$ & 0.6 \\
\hline Hypertension & & $8(26.6 \%)$ & $6(20 \%)$ & $\mathbf{0 . 0 2 *}$ \\
\hline Smoking & & $12(46.6 \%)$ & $9(30 \%)$ & $\mathbf{0 . 0 0 0 6}$ \\
\hline
\end{tabular}


Table (2): Comparison between studied groups for all laboratory parameters

\begin{tabular}{|c|c|c|c|c|c|c|}
\hline Groups & $\begin{array}{l}\text { Healthy } \\
\text { controls }\end{array}$ & Group I & Group II & P1 & $\mathbf{P 2}$ & P3 \\
\hline CD144\% & $4.04+0.74$ & $58.6+5.9$ & $12.9+0.9$ & $<0.0001$ & $<0.0001$ & $<0.0001$ \\
\hline CPK mg/dl & $185.5+17.4$ & $706.5+167.2$ & $814.4+167.7$ & 0.0066 & 0.0013 & 0.6506 \\
\hline CK-MB mg/dI & $16.9+1.3$ & $73.9+9.5$ & $54.1+5.0$ & 0.0001 & 0.0001 & 0.0677 \\
\hline TAT ug/L & 36.4 & 21.9 & 120.37 & 0.0001 & 4.66 & 0.001 \\
\hline CRP $\mathrm{mg} / \mathrm{L}$ & 36.53 & 29.29 & $16.5+5.0$ & $<0.0001$ & 3.86 & 0.001 \\
\hline $\begin{array}{l}\text { Fasting sugar } \\
\mathrm{mg} / \mathrm{dl}\end{array}$ & $99.5+36$ & $190.7+10.1$ & $99.8+2.5$ & $<0.0001$ & 0.9988 & $<0.0001$ \\
\hline HbA1c \% & $5.3+0.1$ & $7.6+0.26$ & $6.5+0.1$ & $\overline{0.0001}$ & $\overline{0.0002}$ & $<0.0001$ \\
\hline $\mathrm{TC} \mathrm{mg} / \mathrm{dl}$ & $162.6+3.5$ & $213.6+11.4$ & $190.3+4.6$ & 0.3620 & $<0.0001$ & 0.0623 \\
\hline TG mg/dI & $113.6+3.1$ & $184.5+15.8$ & $134.5+5.3$ & 0.0002 & 0.0021 & 0.0041 \\
\hline $\begin{array}{l}\text { HDL-cholesterol } \\
\mathrm{mg} / \mathrm{dl}\end{array}$ & $54.6+2.3$ & $45.03+7.6$ & $43.8+3.08$ & $<0.0001$ & $<0.0001$ & 0.4006 \\
\hline $\begin{array}{l}\text { LDL-cholesterol } \\
\mathrm{mg} / \mathrm{dl}\end{array}$ & $85.2+14.9$ & $131.9+55.1$ & $129.6+66.9$ & 0.0001 & 0.0021 & 0.8853 \\
\hline
\end{tabular}

Table (3): Comparison between subgroups for CD144, CK-MB and platelet count:

\begin{tabular}{|l|c|c|c|}
\hline \multicolumn{1}{|c|}{ Parameters } & CD144\% & CK-MB (mg/dl) & Platelet count. \\
\hline Group A & & & \\
\hline Group B & $42.7 \pm 9.3$ & $81.6 \pm 12.2$ & $93.5 \pm 1.1$ \\
\hline Group C & $24.9 \pm 4.8$ & $44.2 \pm 4.9$ & $52.0 \pm 9.2$ \\
\hline P1 & 0.98 & $\mathbf{0 . 0 4 1}$ & 0.79 \\
\hline P2 & 0.07 & $\mathbf{0 . 0 2}$ & $\mathbf{0 . 0 5 5}$ \\
\hline P3 & $\mathbf{0 . 0 5}$ & 0.17 & $\mathbf{0 . 0 1}$ \\
\hline
\end{tabular}

$\boldsymbol{P} \mathbf{1}=$ Group $A$ vs group $B ; \boldsymbol{P} \mathbf{2}=$ Group $A$ vs. group $C ; \boldsymbol{P} 3=$ Group $B$ vs. Group $C$.

Vol. 43, No. 1 \& 2 Jan. \& April, 2014 
Table (4): Comparison of CD144 +ve endothelial microparticles \% (EMP\%) between smoker and non-smoker, hypertensive and normotensive patients in studied groups

\begin{tabular}{|c|c|c|c|}
\hline \multicolumn{2}{|c|}{ Groups } & $\mathbf{X} \pm \mathbf{S D}$ & $\mathbf{P}$ \\
\hline \multirow{4}{*}{ Group I } & Smokers & $68.7+34.9$ & \multirow[b]{2}{*}{0.04} \\
\hline & Non-smokers & $58.1+29.3$ & \\
\hline & Hypertensive & $80.5+22.4$ & \multirow[b]{2}{*}{0.02} \\
\hline & Normotensive & $54.4+31.1$ & \\
\hline \multirow{4}{*}{ Group II } & Smokers & $14.8+4.5$ & \multirow[b]{2}{*}{0.2} \\
\hline & Non-smokers & $12.2+4.9$ & \\
\hline & Hypertensive & $17.3 \pm 5.5$ & \multirow[b]{2}{*}{0.01} \\
\hline & Normotensive & $11.8 \pm 4.0$ & \\
\hline
\end{tabular}

Figure (1): CD144\% among studied groups.

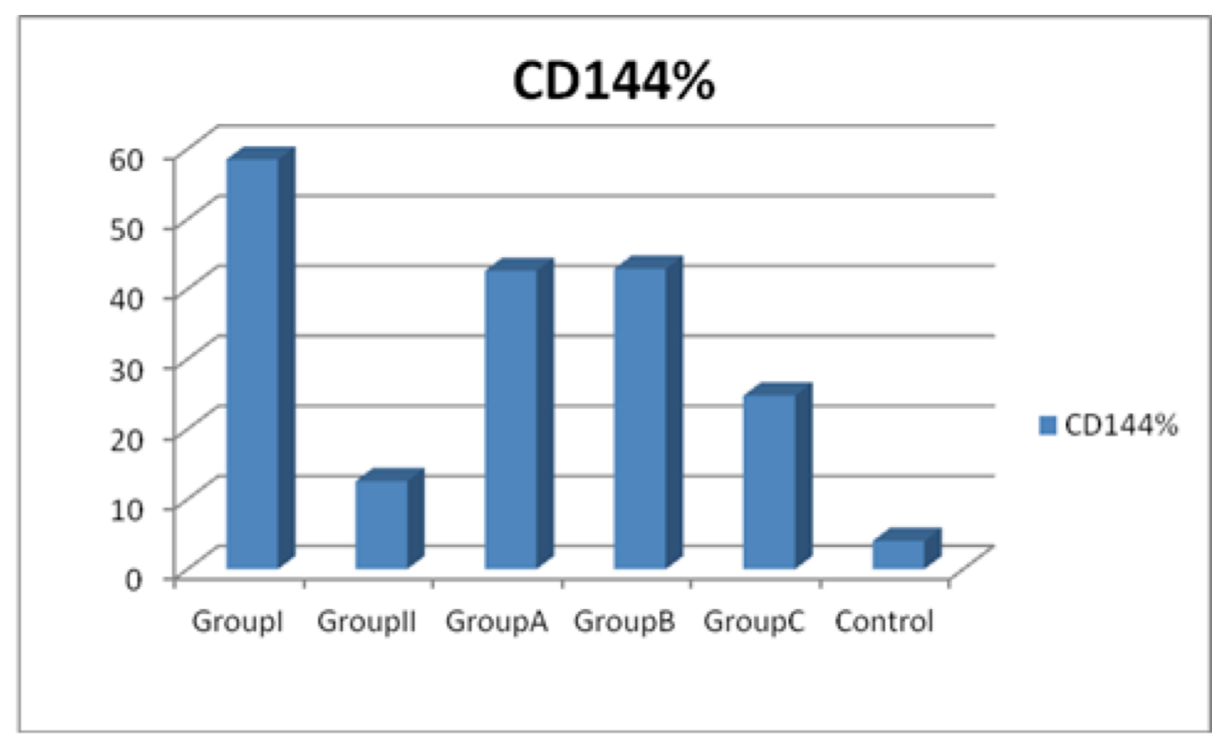

MANSOURA MEDICAL JOURNAL 


\section{DISCUSSION}

Acute coronary syndrome (ACS) is a term that includes all clinical syndromes compatible with acute myocardial ischemia resulting in an imbalance between myocardial oxygen demand and supply. In contrast to stable angina, an ACS results primarily from diminished myocardial blood flow secondary to an occlusive or partially occlusive coronary artery thrombus.

The quantification of circulating endothelial cells (ECs) could indicate the presence of endothelial injury, and is a simple method of evaluating endothelial-related physiologic and pathophysiologic states. Flowcytometry is a method of choice for quantification of ECs. Numerous attempts have been made to standardize flowcytometric protocols, but results from these studies show a high degree of variability among centers (16)

The current study aimed to assess CD144+ EMP in diabetic versus non diabetic ACS patients. Hyperglycemia, hyperlipidemia with reduced HDL-C as well as hypertension are among traditional risk factors for CAD. They have all been independently associated with increased cardiovascular events and are associated with endothelial dysfunction (14).

Our study revealed highly elevated CD144 percentages in diabetic acute coronary syndrome patients compared to healthy control $(p=>$ 0.0001 (highly elevated CKMB, fasting sugar, TC, TG and LDL $(p=0.0001, p=0.0001, p=0.0002$, $p=0.0002$ and $p=0.0001$ respectively). In contrast; non diabetic acute coronary syndrome patients had significantly elevated CD144, CKMB, TC, TG and LDL $(P=0.0001$, $p=0.0001, p=0.0001, p=0.0021$ and $p=0.0021$ respectively) while fasting sugar and $\mathrm{HbA1C}$ were non significantly changed. On the other hand Group B (NSTSEMI) patients had significantly elevated CD144\% in comparison to patients with unstable angina (Group $C) \quad(p=0.05)$ but patients with Group A (STSEMI) had significantly elevated CKMB compared to patients with unstable angina Group C ( $p=0.02)$.

Koga et al. (17) reported that endothelial microparticls and platelets microparticls, work synergistically to achieve maximal procoagulant activity. (17) Consistent with this finding, 
the present study proved that, the increased level of inflammatory marker as CRP and hemostatic marker of thrombin generation as TAT pass paralleled with increased EMP levels CD144 not only markers for endothelial injury/activation and but also contribute to the pathogenesis of vascular injury observed in ACS patients. This finding is consistent with other literature that highlighted that coronary artery disease confer abnormalities of endothelial function and platelet activation (18). Also our study observed variable levels of MPs between patients. These results coinside with Mallat et al. (19) who reported that differences in levels of microparticles reflect differences in medications, however, because heparin has been reported either to have no effect or to decrease microparticles generation from thrombinactivated platelets. This observation suggests that the level of circulating microparticles could be useful as an indicator of the persistence or recurrence of thrombus and therefore as a prognostic marker of the recurrence of ischemic events. (20)

An evidence on the pathophysiological links between EMP formation and vascular dysfunction/damage are provided by studies on hypertension, both systemic and pulmonary. Hypertension causes increased shear stress and direct mechanical damage of arteries. EMPs appear to be very sensitive to hemodynamic changes in hypertension, and their numbers are increased even in mild hypertension and rise further in proportion to blood pressure elevation, even in the presence of multiple risk factors (21).

Moreover, EMP generation is associated with abnormalities of arterial elastic properties in hypertension and persistent arterial elastic abnormalities correlate with EMPs even after blood pressure normalization (22) and our study confirm this as all hypertensive patients from group I and group II had mildly elevated CD144\%.

Platelet count is found to be reduced in diabetic acute coronary patients in the our study, however it is still within the normal reference range. The decreased platelet count may result from its consumption in the process of thrombogenesis in ACS $(23,24)$. CD144+ve EMP might participate in acute coronary syndrome through its procoagulant role. 
Moreover EMP harbor tissue factor, the initiator of extrinsic coagulation pathway leading to thrombin generation. In this respect, Combes et al. (25) reported reduction of clotting time of normal plasma incubated with increasing amount of EMP released in vitro.

The pro-coagulant activity of EMP was confirmed by demonstration that EMP from activated cells triggered TF-dependent thrombin formation in vitro and thrombus formation in vivo (26)

Moreover Montalescot et al. (27) found elevated EMP in infarction related arteries than in the peripheral arteries and suggested that they might participate in ACS through its procoagulant role.

Although the cellular mechanism (s) of the role of EMP in atherosclerosis and CHD largely remain unclear, it may increase reactive oxygen species and enhance cellular apoptosis. On the other hand, the proangiogenic role of EMP may have deleterious effect in many diseases including cancer spread, proliferative diabetic retinopathy and atherosclerotic plaque destabilization by pro- moting intraplaque neovascularization (28).

Endothelial dysfunction and hence elevation of EMP (CD144) could be released by various processes including enhanced oxidative stress. Diabetes mellitus is characterized by an increased tendency for oxidative stress and elevated level of oxidized LDL which represent the nidus for atherosclerosis and CHD. In addition growth factors overexpression are among key players and are indicated as a link between DM and proliferation of extracellular and smooth muscle cells that are active participant in plaque maturation (29).

On the other hand, diabetic state is associated with prothrombotic tendency as well as platelet activation and aggregation which may be the cause of low platelet count in diabetic ACS patients in our study. Peter and Libby $(30)$. reported similar results.

CD144+ve EMP were reported to be lower in STEMI after PCl but not in NSTEMI and stable CAD. Moreover CD144 and monocyte microparticles were independently predictive 
for future admission related to heart failure. Small size microparticles including CD144 microparticles could be potentially implicated in the modulation of post ACS reparative response to injury with prognostic implication. CD144+ve EMP is correlated to CKMB in diabetic acute coronary syndrome patients. This finding is ongoing with Holmes et al. (31) who reported that CD144+ve EMP and platelet microparticles are correlated with myocardium at risk and infarct size especially in STEMI.

Of particular interest, the present study demonstrated significant elevation of CD144+ve EMP in smoker and hypertensive patients compared to non-smokers and nonhypertensive acute coronary syndrome patients respectively. These findings could be explained by a cumulative effect of traditional risk factors in the same patient. Evidence on the pathophysiological links between EMP formation and vascular dysfunction/damage are provided by studies on hypertension, both systemic and pulmonary. Hypertension causes increased shear stress and direct mechanical damage of arteries. EMPs appear to be very sensitive to hemodynamic changes in hy- pertension, and their numbers are increased even in mild hypertension and rise further in proportion to blood pressure elevation, even in the presence of multiple risk factors (32).. Circulating EMP levels were associated with the presence of cardiometabolic risk factors, particularly dyslipidaemia (33).

\section{Conclusion}

The high levels of circulating microparticles of endothelial origin are increased in diabetic patients, and appear to be good predictors of CAD suggesting important role for endothelial injury in prediction of ACS. Hyperglycemia in acute coronary syndrome is associated with enhanced local thrombin generation and platelet activation, as well as unfavorably altered clot features in patients with and without previous history of diabetes.

\section{REFERENCES}

1-Naghavi $M$, Libby $P$, Falk $E$, Casscells SW, Litovsky S, et al. (2003) : From vulnerable plaque to vulnerable patient: a call for new definitions and risk assessment strategies: Part I. Circulation 108: 1664-1672.

MANSOURA MEDICAL JOURNAL 
2-Gupta M, Tabas JA, Kohn MA

(2002) : Presenting complaint among patients with myocardial infarction who present to an urban, public hospital emergency department. Ann Emerg Med;40:180-6.

3-Daleke DL (2003) : Regulation of transbilayer plasma membrane phospholipid asymmetry. J Lipid Res; 44: 233-242.

4-Creager MA, Lüscher TF, Cosentino $F$, Beckman JA (2003) : Diabetes and vascular disease: pathophysiology, clinical consequences, and medical therapy: part I. Circulation; 108 (12):1527-1532.

5-Habib SS (2012) : Cardiovascular disease in diabetes: Role of dyslipidemia, thrombosis and inflammation. Basic Research Journal of Medicine and Clinical Sciences ISSN 2315-6864Vol. 1(3) pp. 33-42.

\section{6-Chironi GN, Boulanger CM,}

Simon A, Dignat-George

F, Freyssinet JM, Tedgui

A (2009) : Endothelial microparticles in diseases. Cell Tissue Res; 335: 143-51.

7-Feng B, Chen Y, Luo Y, Chen M, Li X, Ni Y (2010) : Circulating level of microparticles and their correlation with arterial elasticity and endothelium dependent dilation in patients with type 2 diabetes mellitus. Atherosclerosis ; 208: 264-9.

8- Bulut D, Maier K, Bulut-Streich N, Borgel J, Hanefeld C, Mugge A (2008) : Circulating endothelial microparticles correlate inversely with endothelial function in patients with ischemic left ventricular dysfunction. J Card Fail; 14: 336-40.

9-Boulanger CM, Amabile N, Tedgui A (2006) : Circulating microparticles: A potential prognostic marker for atherosclerotic vascular disease. Hypertension 2006; 48: 180-6. 
10-Bernard S, Loffroy R, Serusclat

A, Boussel L, Bonnefoy E, Thevenon C, Rabilloud M, Revel D, Moulin P, Douek P (2009) : Increased levels of endothelial microparticles CD144 (VE-Cadherin) positives in type 2 diabetic patients with coronary non-calcified plaques evaluated by multidetector computed tomography (MDCT). Atherosclerosis; 203: 429-35

11-Shet AS, Aras O, Gupta K, Hass MJ, Rausch DJ, Saba N, Koopmeiners L, Key NS, Hebbel RP (2003) : Sickle blood contains tissue factor positive microparticles derived from endothelial cells and monocytes. Blood; 102: 2678-83.

12-Libby P (2008) : The molecular mechanisms of the thrombotic complications of atherosclerosis. J Intern Med; 263:517-27.

13-Wahab NN, Cowden EA, Pearce NJ, Gardner MJ, Merry H,
Cox JL (2002) : Is blood glucose an independent predictor of mortality in acute myocardial infarction in the thrombolytic era? J Am Coll Cardiol 40:1748-1754.

14-Norhammar A, Tenerz A, Nilsson G, Hamsten A, Efendic S, Ryden L, Malmberg K: (2002) : Glucose metabolism in patients with acute myocardial infarction and no previous diagnosis of diabetes mellitus: A prospective study. Lancet 359:2140-2144.

15-Garcia S, Chirinos J, Jimenez J, et al (2005) : Phenotypic assessment of endothelial microparticles in patients with heart failure and after heart transplantation: switch from cell activation to apoptosis. J Heart Lung Transplant; 24: 2184-2189.

16-Mobarrez F, Antovic J, Egberg $\mathrm{N}$, Hansson $\mathrm{M}$, Jorneskog G, Hultenby $\mathrm{K}$, Wallen $\mathbf{H}$ (2009) : A multicolor flow cytometric assay for meas- 
EVALUATION OF PROCOAGULANT POTENTIAL etc...

urement of platelet-derived

microparticles. Thromb

Res; 125: e110-6

17-Koga H, Sugiyama S, Kugiyama K, Watanabe $K$, Fukushima H, Tanaka T, Sakamoto $T$, Yoshimura $M$, Jinnouchi $H$, Ogawa $H$ (2005) : Elevated levels of VE-cadherin-positive endothelial microparticles in patients with type 2 diabetes mellitus and coronary artery disease. J Am Coll Cardiol; 45: 1622-30.

18-Ahn YS, Jy W, Jimenez JJ, Horstman LL. More on (2004) : Cellular microparticles: what are they bad or good for? J Thromb Haemost; 2:1215-6.

19-Mallat $Z$, Benamer $H$, Hugel B, Benessiano J, Steg PG, Freyssinet JM and Tedgui A. (2000) : Elevated levels of shed membrane microparticles with procoagulant potential in the peripheral circulating blood of patients with acute coronary syn- dromes. Circulation; 101:

841-843.

20-Jones WS, Annex BH (2007): Growth factors for therapeutic angiogenesis in peripheral arterial disease. Curr Opin Cardiol. 22; 458-463.

21-Preston RA, Jy W, Jimenez JJ, Mauro LM, Horstman LL, Valle M, Aime G, Ahn YS (2003) : Effects of severe hypertension on endothelial and platelet microparticles. Hypertension 2003; 41: 211-7.

22-Wang JG, Manly D, Kirchhofer D, Pawlinski R, Mackman N (2009) : Levels of microparticle tissue factor activity correlate with coagulation activation in endotoxemic mice. $\mathrm{J}$ Thromb Haemost; 7: 1092-8.

23-Lukasik M, Rozalski M, Luzak B, Michalak S, Kozubski W, WatalaC (2010) : Platelet activation and reactivity in the convalescent phase 
of ischaemic stroke.

Thromb Haemost; 103:

644-50.

24-Morel O, Pereira B, Averous G, Faure A, Jesel $L$, Germain $\mathbf{P}$, Grunebaum L, OhImann $P$, Freyssinet JM, Bareiss $\mathbf{P}$, Toti $\mathbf{F}$ (2010) : Increased levels of procoagulant tissue factorbearing microparticles within the occluded coronary artery of patients with STsegment elevation myocardial infarction: Role of endothelial damage and leukocyte activation. Atherosclerosis; 204: 636-41.

25-Combes V, Simon AC, Grau GE, Arnoux D, Camoin L, SabatierF, Mutin M, Sanmarco M, Sampol J, Dignat-George F (1999) : In vitro generation of endothelial microparticles and possible prothrombotic activity in patients with lupus anticoagulant. J Clin Invest; 104: 93-10226.

26-Abid Hussein MN, Boing AN,
Biro E, Hoek FJ, Vogel GM, Meuleman DG, Sturk A, Nieuwland R (2008) : Phospholipid composition of in vitro endothelial microparticles and their in vivo thrombogenic properties. Thromb Res; 121: 865-871.

27-Montalescot G, Cayla G, Collet JP, Elhadad S, Beygui $\mathbf{F}$, Le Breton $\mathrm{H}$ et al. (2009) : "Immediate versus delayed intervention for acute coronary syndromes: A randomized clinical trial.". JAMA 302 (9): 947-54.

28-Leroyer AS, Rautou PE, Silvestre JS, Castier Y, Leseche G, Devue C, Duriez M, Brandes RP, Lutgens E, Tedgui A, Boulanger CM (2008) : CD40 ligand+ microparticles from human atherosclerotic plaques stimulate endothelial proliferation and angiogenesis, a potential mechanism for intraplaque neovascularization. J Am Coll Cardiol; 52: 1302-11.

MANSOURA MEDICAL JOURNAL 
29-Wackers FJ, Young LH, Inzucchi SE, et al (2004) : Detection of silent myocardial ischemia in asymptomatic diabetic subjects: the DIAD study. Diabetes Care; 27:1954-61

30-Peter and Libby (2013) : Mechanisms of acute coronary syndromes and their implications for therapy. $\mathrm{N}$ Engl J Med; 368:2004-13. platelet microparticles. Thromb Haemost; 82: 794-800

\section{1-Holmes Jr, Lerman A, Moreno} PR,King SB III, Sharma SK (2013) : Diagnosis and management of STEMI arising from plaque erosion. JACC C ardio- vasc Imaging; 6:290-6.

32-Simak J, Gelderman MP, Yu H, Wright V, Baird AE (2006) : Circulating endothelial microparticles in acute ischemic stroke: A link to severity, lesion volume and outcome. J Thromb Haemost; 4: 1296-302.

33- Park SM, Angel CE, McIntosh JD, Mansell CM, Chen CJ, Cebon J, Dunbar PR. (2014) : Association of circulating endothelial microparticles with cardiometabolic risk factors in the Framingham Heart Study. Eur Heart J, Apr 14;9 (4):e94781. doi: 10.1371/ journal.pone.0094781. 